\title{
Designing educational escape rooms: validating the Star Model
}

\author{
Luca Botturi, Masiar Babazadeh \\ Scuola universitaria professionale della Svizzera italiana, Dipartimento formazione \\ e apprendimento \\ luca.botturi@supsi.ch,masiar.babazadeh@supsi.ch
}

\begin{abstract}
Escape games have become popular nowadays. Groups of people are locked inside riddles-filled rooms and have to work their way out finding clues and solving puzzles. While being fun for groups or team building, escape games have a great educational potential, which can be capitalized if teachers integrate them in their professional activities. In this paper we introduce the Star Model, a tool for teachers to design and play their own educational escape rooms, which was built on top of previous literature and experiences. We present and discuss its validation through a pre/post survey involving 50 primary secondary school teachers who participated in a course about educational escape rooms. The model validation suggests that the Star Model can be proposed as a valid tool for educational escape rooms design.
\end{abstract}

Keywords: Educational escape rooms, teacher education, game design, model, validation.

\section{Introduction and Motivation}

Escape rooms (ERs) are an entertainment phenomenon that became increasingly popular in the early 2010s and can nowadays be found in many cities around the world [1]. Teams, usually of 4 to 8 players, are locked in a puzzles-filled room: their goal is to exit the room within a limited amount of time by solving puzzles. Escape rooms are usually developed around a theme or a narrative, with puzzles of different kinds - riddles, matching, calculations, etc. - and can be implemented with physical items (e.g., padlocks, chains, etc.), on the web, or with Augmented Reality (AR) or Virtual Reality (VR) systems. ERs are usually played by groups of friends for fun or as a team building activity.

Such format can also be effectively applied to education, both in formal and informal settings, and it has come to represent a new area in the serious games domain. Both the theme/narrative and the puzzles can support the achievement of specific subject-related learning goals through the gameplay [2]. Besides, ERs also enhance the development of soft (or transversal) skills [3] making them an interesting and versatile tool to be used in a classroom context in order to develop critical and creative thinking, communication, and collaboration skills, along with problem solving, time management, and resilience.

As for any new educational practice or tool, the key for the actual integration of ERs in schools is teacher education. In order to exploit the learning potential of ER, teachers should be able to understand how ERs work both for playing ready-made ERs in class, and for designing their own ones in case they wish to, or even engaging in ER design with their pupils. This paper is about a design model conceived to support the integration of ERs in education, and its validation with 50 secondary school teachers. 
Before proceeding further, it is important to point out that the design and implementation of ERs requires different tools and objects, and a dedicated space, which are not always available in a school setting. For this reason, in many instances, escape boxes provide a feasible alternative to leverage on a similar (even if less immersive) gameplay in a more sustainable fashion [4]. The model presented in this paper can be easily adapted to escape boxes.

The paper is structured as follows. In Section 2, we provide a summary of the current literature on the topic. In Section 3 we introduce the Star Model, illustrating its logic and consistence from a theoretical point of view. In Section 4 , we present the methods and results of the validation. Finally, in Section 5, we draw some conclusions and outlooks.

\section{State of the Art}

The exploitation of ERs as a new game-based learning format is a recent topic, and has been analyzed by few studies, which introduced the concept of Educational Escape Room (EER).

Most published studies are informal or case-based [5]. For example, an EER activity in Higher Education has been presented in [6], where the authors study the use of a toolbox gaming strategy based on ER concepts to help students learn about cardiovascular medications in a Pharmacology course. The results of a test with the course participants encourage further research about non-traditional learning activities such as escape games. Another case related to medical studies has been presented in [7], where the authors show the design and implementation of a vascular surgery-themed EER. The results of the tests carried out with small groups of participants suggest that the pilot project created a new learning experience by combining puzzles, riddles, and manual techniques. Both studies lack to show the actual evaluation methodology and the model that guided the EER design.

A similar activity is shown in [8], where authors proposed a Physics-themed escape room for high school students. The presented puzzle aimed to teach students about the physics of fluids, a topic often left out in the authors' high school curriculum. Through the use of a Kahoot quiz, authors gathered feedback from the participants. The paper reports an engaging and "flow"-inducing activity [9] that was well perceived by students and that also helped them understand physics concepts. The paper does not clearly state which model was used to design the EER that was presented.

In [10] the authors investigated whether escape games can be used as a teaching tool in the context of educational robotics by developing and testing an escape game with Thymio robots. Participants with a wide age range had to learn how to program a Thymio in order to successfully escape the room. The results of the preliminary tests suggest that escape games provide a favorable framework for educational robotic activities, claiming that it puts collaborative learning and self regulation into practice. Another example of EER aimed to teach programming can be found in [11], where authors present a paper- and computer-based escape game experience in Higher Education. Neither study indicates if a model was used to design the presented EERs, or if it was based on prior ER experiences.

The survey presented in [12] summarizes the state of the art of EERs activities by analyzing 68 papers published in the decade 2009-2019. Interestingly, the number of articles on this topic started skyrocketing in 2017. The results provide a general overview of the current research, by showing metrics on game type, location, team size, time limit, advantages and challenges, and highlight the potential of EERs in supporting teaching and learning. The authors indicate that most of the surveyed EERs report powerful engagement/enjoyment/motivation, along with teamwork and social interaction. One-third of the studies also report a generic learning gain. While most of the research on EERs focuses on the evaluation of ERs in education - namely on their impact on motivation and on the development of subject-matter-related 
competences and life skills - many studies suffer from poor evaluation (e.g., the lack of a control group) and small sample size [12]. The authors suggest that further studies in the evaluation and debriefing of EERs would therefore be beneficial.

Such an approach is definitely relevant, but it only tells part of the story: as any instructional device or approach, the evaluation of EERs cannot be separated from their design. Indeed, an EER will only be effective if it has been properly designed, developed and implemented, and not just from its "being an EER" (whatever it would mean in practice). Under this respect, the EscapED framework [13] aims to support the creation of EER and interactive gaming experiences for staff and students in Higher Education. The framework provides an ordered list of six main steps that can be followed during the design and development phase, and includes an evaluation phase. After conducting a pilot trial, the authors conclude suggesting there are significant reasons to explore such game-based learning activities. The present work can be considered an elaboration and extension of EscapeED.

Finally, it is interesting to notice that most of the current body of research regarding ERs in education focuses on post-compulsory education, i.e., high-school or university education [12], especially in Healthcare, Natural Sciences, Social sciences and in relation to Digital technologies. Nonetheless, EERs are being used in compulsory education as well [4], and for basically all subjects. The present work stems from the application of ER in primary and secondary education.

\section{Framing educational escape rooms: the Star Model}

This study stems from School Break (http://www.school-break.eu), a project funded under the Erasmus+ Programme, which is about the development of tools, training, and exemplary materials for fostering the uptake of EERs in secondary education. As part of its activities, the SchoolBreak team developed 3 teacher handbooks [14] [15] [16] and a set of EERs on various curriculum-related topics, distributed freely on the project website in different languages.

One of the major concerns of the project was to outline a training program to enable preservice and in-service teachers to (a) use EERs in their classes; (b) design their own EERs; and (c) design ERs with their students. This required a conceptualization of the key elements of an effective EER, which were then framed into a design model to be used as advance organizer [17] in the training program. The model was labelled Star Model, and we asked ourselves if it was understandable, usable and if teachers actually used it. This paper reports our efforts to validate the Star Model with data collected from 50 pre-service and in-service teachers.

How can we describe an educational escape room in terms of design? What are the elements that we should think of, develop and match with one another in order to generate an effective and engaging game-based learning experience? As for all game-based learning experiences, the design of an EER blends together elements from game design and instructional design, in order to generate an original game cycle geared to learning [18].

ER and EER design is a novel field, in which only few specific tools are available. For example, [19] reports using a generic experience design model to steer the development of a commercial ER, but most studies focus on the assessment of EER without providing elements about their design, such as [7, 8, 10, 11, 20-22]. To the extent of our knowledge, so far only the recently published EscapED model [13] provides an explicit design tool for EERs - and indeed it offered a sound starting point for us as well. This model include a sequence of 6 elements that generate a design process: participants, objectives, theme, puzzles, equipment and evaluation. EscapED was never fully validated, but assessed through the feedback of 8 players of an EER designed with the model, and then through the account of an external 
Learning Designer that applied it. Our first experience both in the design of EERs and in teacher education were also based on EscapED, and four issues emerged:

1. Designing ERs is not only about combining a theme or narrative with puzzles, but also creating a meaningful structure or flow through which the players proceed during the game. In the game design literature this is usually called game-flow [23], and it becomes even more important in ER were groups are supposed to work together, as it is often the case in a class setting. Moreover, Nicholson's work emphasized the range of different game-flows that can give shape to ERs [24], an element which we thought should be proposed to novice teacher-designers as a central design decision.

2. Serious games literature has emphasized the role that debriefing has in completing the learning cycle: the debriefing is where in-game learning emerges and becomes aware. In the EscapeED model, "reflection" only appears as part of the Evaluation element, and its importance is reprised in the game developer report included in the paper. While it is clear that the feedback that can be collected from the debriefing is relevant to the evaluation of an ER, just like any evidence about actual learning (e.g., the results of a test), in our experience the debriefing requires a careful and separate design from the evaluation and, from the teacher's point of view, it represents an activity with a distinct finality (i.e., helping pupils to complete their learning cycle vs. evaluating the game-based learning activity).

3. ERs in school setting often have to take time, space, resources and other constraints into account. Such elements were present in EscapED, but were scattered across the Participants and Equipment elements, so that we felt they were not given the required emphasis.

4. Finally, while iteration items are included in the Evaluation element, the presentation and graphical visualization of EscapED suggests a linear process, which we felt was not realistic. In our experience the design process can start from any element, and often moves back and forth trying to achieve a balance, seldom following a purely linear pattern. This is also the conclusion of the decade-long debate around Instructional Design models [25]: a design model helps keeping consistency, but can make design ineffective and frustrating if it suggests too rigid an approach.

Our model, which we labelled Star Model because of its visualization and which is illustrated in Figure 1, is a proposal to overcome such limitations without missing all the insights gained with EscapED. The Star Model suggests non-linearity and interdependence among its five game elements and four context elements, which are organized in two distinct layers. It was specifically designed to offer teacher guidance in EERs design.

\subsection{Game elements}

From a design point of view, an EER is a game composed of five key elements, represented as the points of the star. Four of them are proper of entertainment ERs, while the fifth element introduces the learning dimension [5].

(1) The Narrative is the story heartbeat that pulses life into the game. The narrative provides an overarching theme that - if consistently developed - can support the immersiveness of the experience and promote engagement. The narrative should assign an active role to the players, who are not just spectators [26], and it also suggests the ER mode or type: escaping a prison, solving a mystery, liberating hostages, etc. The narrative (or theme) is a key feature to support meaningful play [23], i.e., a game in which "puzzles and tasks are not simply there to be barriers to winning the game, but each challenge has a purpose and is tied into the larger narrative, giving the player a way to find meaning in their actions." [2]

(2) The Game-Flow describes the structure of the game experience for the players. Typi- 


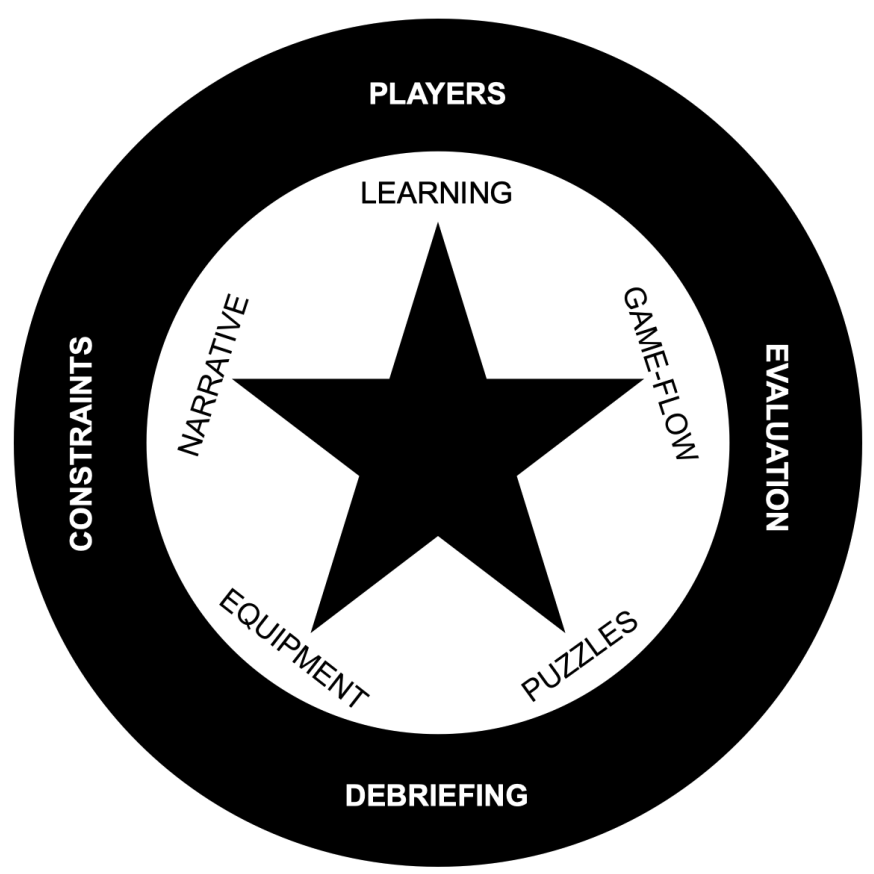

Figure 1: The Star Model

cally, an ER has different phases (an introduction into the escape room "world" and narrative; an exploration, solving different puzzles to get a code, unlocking a big challenge, etc.). Activities within an ER can be sequential or parallel or follow more complex patterns [27]. While commercial ERs are usually designed for a few people that play collaboratively [24], EERs are often designed to host classes of up to 20+ students. Groupings are part of the game-flow design. When multiple players or groups play an ER, they can be competitive and/or collaborative. Of course, as a teacher, ensuring active participation of everyone within groups is very important [4].

(3) Solving an escape room means solving a set of Puzzles, which are the "tools" of an ER [28]. Finding objects in a room, breaking a code, translating sentences, doing math, building objects from components, programming, etc. Different types of puzzles can be found in ERs [4]: (a) cognitive puzzles, that require thinking skills and logic, are probably the most commonly used [29]; (b) physical puzzles, that require body movements or manipulation; and (c) metapuzzles, i.e., puzzles which bring together results from the other ones, and are often connected to the narrative in key points of the gameplay. Matching puzzles to learning goals is often the hardest challenge in EERs design. Also, puzzles should be clear, i.e., they should look like items that require a solution, and provide a clear feedback when solutions (correct or incorrect) are tested. The provision of specific hints and or hint rules (when should a hint be given? How?) is also part of puzzle design [30].

(4) An escape room materializes into a set of coordinated Equipment items, physical and/or digital. They include (a) the room itself as a space; (b) the items that generate the narrative, e.g., a video introduction or printed documents, or props that embody the theme or setting; and (c) the elements that implement the mechanics of the game, and that should be manipulated in order to solve the puzzles (crosswords, riddles, sudokus, hidden clues, etc.), including technological elements (a projector, lights, loudspeakers, etc.), lockers or other blocking elements (padlocks, chains, passwords, etc.), a stopwatch, etc.

These four elements describe a generic, leisure or educational, ER. When an ER is specifically designed as an educational activity, one additional element comes into play, namely: 
(5) The envisaged Learning process, which is actually the reason of existence of an EER. This entails (a) the targeted learning outcomes in terms of (extra-)curricular content, (inter- or multi-) disciplinary competences, and soft skills; and (b) the expected learning process, e.g., how the learning should take place. Is the content to be learned part of the background story? Are specific competences developed through puzzle solving? Etc. Within the Star Model we attribute this element a broader meaning than the objectives in the EscapeED model [13].

As with any game, all elements should be consistent with each other: if each element has a reason for being part of the game experience [2], this will make the escape room interesting, engaging, and effective. During the design process, the five elements should connect to each other to form a seamless experience. For example, the puzzles in an ER should be consistent with the storyline, and their solution should carry it meaningfully forward; also, puzzle and narrative should support learning; etc.

Nonetheless, they are also independent, i.e., each one of them can be (at least partly) changed without necessarily requiring to change the others. For example, a designer might decide to change a single puzzle (e.g., after a revision): the new puzzle should of course match the narrative and the props, but in principle that would not necessarily require major changes; or, to adapt the game-flow to multiple groups without changing the narrative and learning elements. For those familiar with game design, these elements correspond to traditional game design elements [23]: the narrative/theme corresponds directly, the game-flow corresponds to the game design, the puzzles correspond to the game mechanics, and the equipment corresponds to the game interface. The elements and their interrelations can be understood as design layers [31].

\subsection{Context elements}

While the five game elements generate the inner design of a game, the design of an EER should be informed by its context. The Star Model defines four relevant dimensions that should be analysed before starting the design process and that influence all the above-mentioned design elements.

(1) The Players, who are often students, and have specific characteristics (demographics, attitude towards the subject matter or content, attitude towards playing for learning, etc.), and that can be of a specific number (e.g., classes of 15 , or 20, or 25 students). Understanding your players corresponds to the regular "learner analysis" included in most Instructional Design models [25].

(2) Possible time and space Constraints, which are usually quite tight in a regular school setting; e.g., available space (the room might be small; or there might be multiple rooms available), or time (e.g., if the escape room must be played within a specific school period), or the availability of specific equipment, etc. The learning outcomes themselves also constrain the content of the escape room, for example because they have to match the curriculum (which is also a form of design constraint). This can be intended as a "context analysis".

(3) How designers intend to conduct the Evaluation of the escape room. This is different even if complementary - to the evaluation of the learning that takes place in the escape room. Arnab and Clarke [32] understand evaluation as a main component in game-based learning development: designers should identify specific moments to observe, or specific artefacts to collect and analyse afterwards, or specific questions or feedback to be collected from players after the game.

(4) Finally, the Debriefing is a key (but often overlooked [5, 12]) after-game phase in which the learning cycle is completed [33], and the playing experience is connected to the learning context. In fact, after the game rush, players should be made aware of the learning that occurred during the gameplay, and should be helped to connect it to prior learning and to 
the broader learning process in which the EER is included.

\subsection{A process for educational escape room design}

Designing an (educational) escape room is not an easy task: a room has many components and their interrelatedness might seem to be a formidable challenge for novices. The Star Model presented above provides a map of the territory, but does not suggest any specific path to be followed. While a generic reasonable and effective design process can be devised (and should be tentatively followed), any design activity will inevitably move back and forth from one element to the other, striving to follow inspiration and ideas (which may come from any point and at any time), and at the same time to keep the overall design consistent.

In principle, as suggested by most Instructional Design models (e.g., [25]) the design of an EER should start from the definition of the expected learning outcomes (Learning) in relation to the potential Players and from the identification of Constraints (time, space, staff available). The designer should then find a core theme or Narrative, and within that narrative develop a suitable Game-Flow (defining groupings, phases, etc., e.g., by drawing a map of the ER) and then proceed to develop the Puzzles. Specific Equipment (both technical and props) will be defined as the design moves along. Finally, the Debriefing should be carefully designed. As mentioned, this is where the learning part of an EER emerges, is made aware and connected to the actual goal of the experience. Reflection - both on how the players played the game and on the game content - is therefore crucial.

It is impossible to overstate the importance of play-testing in this process [28]; players never behave as you expect them to and it is only by having your game played over and over that you will be able to create a robust EER. Play-testing at all stages, as neatly exemplified in [4], is absolutely crucial in order to develop a game that is both educational and fun to play: testing the individual puzzles, paper prototypes and the full game at different stages will provide important feedback to improve the design. As for any game, play-testing is also fundamental in order to achieve game balance and playability [34]. Experience tells that also the debriefing structure could and should be tested, as the game might provide different "hooks" to address learning, and that might work differently in different situations.

In most EERs publications teachers report the massive time investment and the lack of resources [12]. Designing an EER must also include thinking about its actual feasibility in the school setting. This includes the consideration of budgetary aspects and many practicalities of ERs management, trying to enable fast and easy handling [4]. Also, the ease of resetting the room to play again, i.e., playing it over again with different players/groups/classes, which is often the case in an educational setting, should be considered.

Finally, while it is quite possible for a single person to design a room, the ongoing process of critique and refinement that takes place when working as a team can be invaluable. To this end, the Star Model can also be used as a shared overview to distribute and coordinate the work.

\section{Validating the Star Model}

\subsection{Training teachers to use and design educational escape rooms}

The Star Model was developed with the precise aim of providing an overview of the elements to be considered in the design of EERs. While it is based on solid previous game and instructional design work, it could just remain a neat theoretical tool, but not appealing or usable for its main intended public, namely, teachers. In order to validate the model, it was embedded in 
three teacher education courses focused on EERs use and design at the Department of Education and Learning of the University of Applied Sciences and Arts of Southern Switzerland, the Italian-speaking teacher education university of Switzerland. The details of the courses are illustrated in Table 1

\begin{tabular}{l|l|l|l|l|l} 
Course & Program & Sector & Participants & $N$ & Hours \\
\hline A & Master in education & Lower sec. & Pre-service & 16 & $16 \mathrm{~h}$ \\
B & Continuing education & Lower sec. & In-service & 25 & $20 \mathrm{~h}$ \\
C & Continuing education & Primary & In-service & 20 & $20 \mathrm{~h}$ \\
\hline
\end{tabular}

Table 1: Details of the courses

All courses shared the same learning goals, namely: understanding the key concepts of game-based learning in relation to EERs; integrating EERs in your own teaching; designing and developing your own EERs; planning ER design activities with pupils. The reference materials were the School Break handbooks [14-16], which include the Star Model.

Enrollment in the courses was voluntary (course A, in Table 1, was one option within a larger Master course). All of them gave credits on completion if attendance was above 4/5 of all contact hours (cf. the "Hours" column in Table 1) and an EER was developed as output of a group work. About half of the contact hours were devoted to game experiences and reflections, and the other half was dedicated to the design and review of EERs.

The institutional regulations of the university in which the courses took place did not require a formal approval from the Ethics committee for a study which only involved adults and surveys. Nonetheless, all the participants were duly informed about the study and its goals, with a clear indication that their participation was voluntary and that they could withdraw at any time.

\subsection{Method}

Based on the Instructional Design tradition in model validation [35], we decided to focus on internal validation, i.e., considering the model formal features and its use. As for formal features, our validation addressed the model's clarity and completeness; as for its use, it included both its perceived utility and actual use. These four concepts where transposed to the following six research questions, where clarity has been operationalized in three aspects, namely, overall clarity, elements clarity, and clarity of relationships:

1. Is the model globally understandable? (overall clarity)

2. Are its individual elements understandable? (elements clarity)

3. Does the model straightforwardly illustrate the relationships among the elements? (clarity of relationships)

4. Is the model complete, or are some key elements missing? (completeness)

5. Did teachers actually use the model while designing their own EERs? (actual use)

6. Do teachers think that the model is in general useful for the design of EERs? (utility)

A post-course survey was developed in order to collect teachers' assessment on the model along these six research questions. The survey is available in Annex 2. Overall, 50 teachers filled in the survey: 17 in-service primary school teachers, 18 in-service secondary school teachers and 15 pre-service secondary school teachers.

For courses B and C, a pre-course survey was also delivered (cf. Annex 1), in order to track both the participants' previous knowledge and experiences and to collect their self-assessment in relation to the course goals, using the following items:

1. I know where to find good EERs for my class 
2. I know where to look for resources for creating my own EER

3. I can prepare for playing an EER with my class

4. I feel I can handle playing an EER with my class

5. I can integrate an EER with the other learning activities in my plan

6. I can use an EER to actually enhance learning of my pupils

7. I can use an EER for the assessment of my pupils

8. I can design a new EER

In that case the post-course survey included matching items, so that for 24 participants it was possible to calculate the self-assessment delta in relation to the learning goals. 29 inservice participants also declared their age of service: 7 teachers were beginners (less than 5 years in the profession), 9 were advanced (between 5 and 10 years) and 8 were experts (more than 10 years). Unfortunately, we could not deliver any pre-course survey for course A.

All evaluation items in the surveys were collected using 4-points Likert scales, from 0 (lowest/"I do not agree") to 3 (higher/"I completely agree"). Results were elaborated based on frequencies; given the sample size, only descriptive statistics were used.

\subsection{Results}

First of all, the courses overall received a very positive evaluation. For the continuing education courses, 36 out of the 37 respondents indicated they would like to register for a follow-up course, and 34 would recommend the course to their colleagues. All teachers confirmed they intend to actually use and design EERs for their classes, while fewer plan to design ERs with their pupils.

The self-assessment of ER use and design competences ( $\mathrm{N}=24$, only in-service teachers who completed both the pre- and post-course surveys) indicated a general perception of improvement: on average, the self-assessment of each competence increased by 1.19 (on a scale from 0 to 3), ranging from a maximum for "I can design a new EER" (1.83) to a minimum for "I feel I can handle playing an EER with my class" (0.83). On average, secondary school teachers' self-assessment indicate a larger increase (1.42) than primary school teachers (0.97). These results suggest that the course overall, which was based on the Star Model, was successful, at least according to the participants' short-term satisfaction.

The evaluation of the Star Model ( $\mathrm{N}=50$, including both in-service and pre-service teachers) also yielded overall positive results, with a global average score across the above-mentioned six items of 2.16 on a 0 -to-3 scale. Figure 2 illustrates the results for each item, and adds a global value, which is calculated as the average of the six items.

The model appears to be understandable both overall (2.28) and by element (2.34) and especially complete (2.40), i.e., according to the participants it captures all relevant elements in EERs design. To a lower extent, the model is able to represent the relationships among its elements (2.0). Teachers find the model useful (2.10) and seem to have actually used it in their design work (1.84; the answer of 35 out of 50 participants was 2 or 3 , i.e., in the positive part of the Likert scale).

The model evaluation results show interesting differences if we consider the three groups in the three courses (Figure 3).

As the design of the courses in general and for the individual sessions was alike, we can assume that such differences depend on the different perception of these three types of teachers. Secondary school teachers seem to like the model more (global average 2.33 for in-service teachers and 2.22 for pre-service teachers) than primary school teachers (global average 1.93). While pre-service secondary school teachers seem to have appreciated the completeness of the model, in-service ones have a remarkably higher score on relationship and actual use. A possible interpretation is that pre-service teachers were looking for an overview of the elements 


\section{Global evaluation}

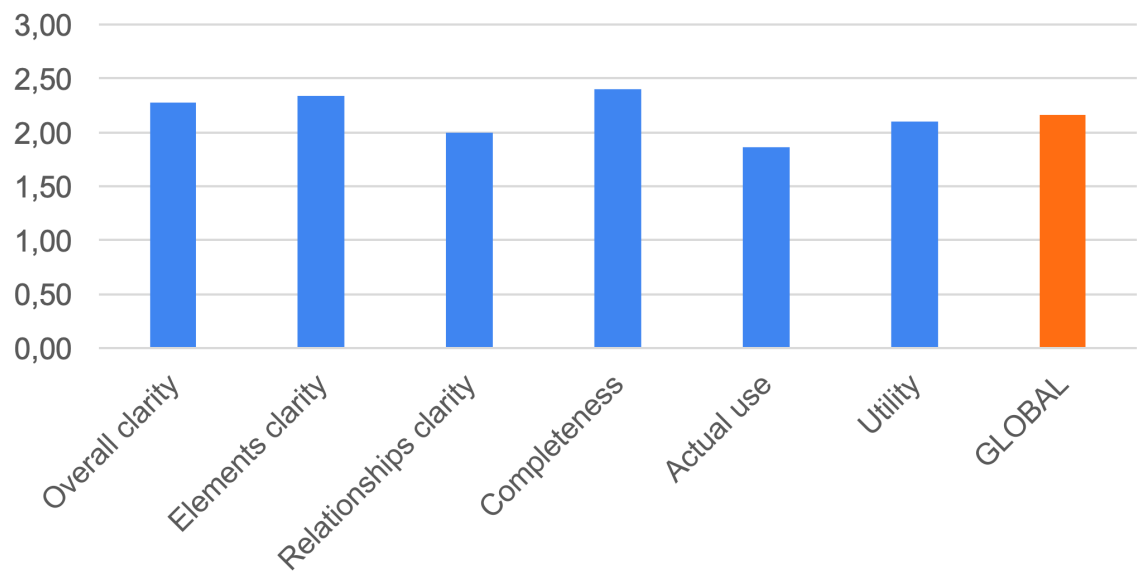

Figure 2: Global model evaluation $(N=50)$

\section{Evaluation by sector}

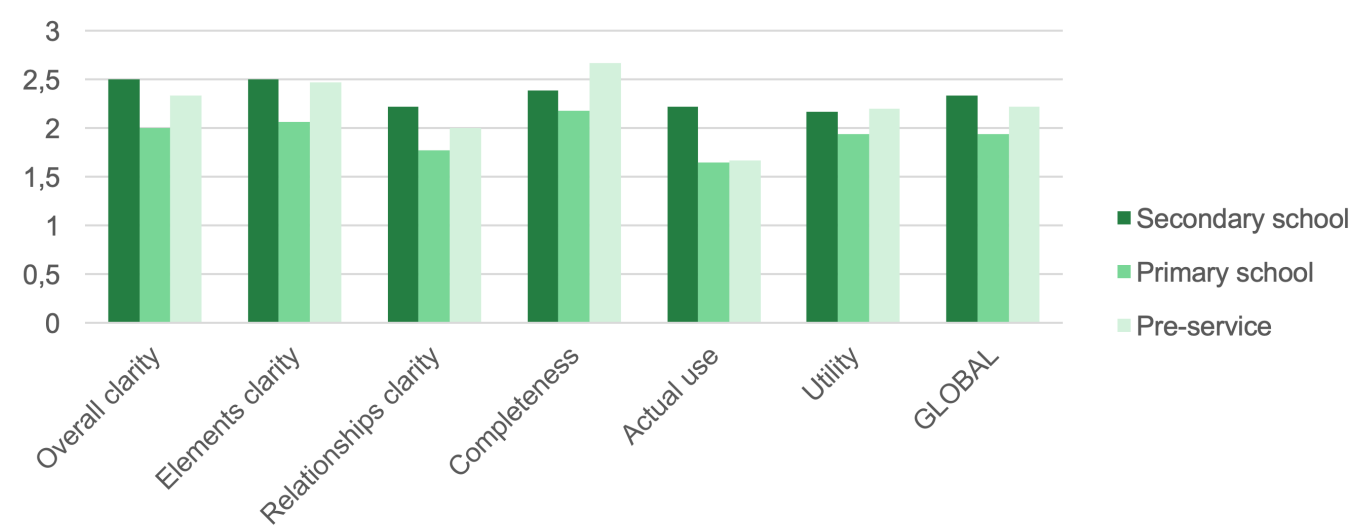

Figure 3: Model evaluation by sector $(N=50)$

in involved in this type of instructional game design in order to reduce complexity, while in-service teachers, who are in general more used to handle complex instructional designs, looked for more step-to-step guidance through the design process, focusing on "doing the design" and on interrelations. On the other hand, the relatively lower scores provided by primary school teachers raise some questions: is the model too complex to be clear and useful? Would they prefer a different approach? It is important to consider that both the background and professional profile of primary and secondary school teachers in Switzerland is very different: primary school teachers are generalist teachers (i.e., they teach all subjects to just one class) and have a 3-year vocational Bachelor degree in teaching; secondary school teachers are subject specialists (i.e., they teach just one subject to more classes) have at least a disciplinary Bachelor or Master degree plus a 2-year vocational Master in teaching.

Finally, the experience (age of service) of the participants also seems to have an influence on their reception of the Star Model (Figure 4).

The analysis was conducted only on the 29 in-service teachers that declared they age of service. Interestingly enough, more experienced teachers appreciated the model the most (experts: 2.35; advanced: 2.32) than novice teachers (1.83). This is consistent across the 


\section{Evaluation by experience}

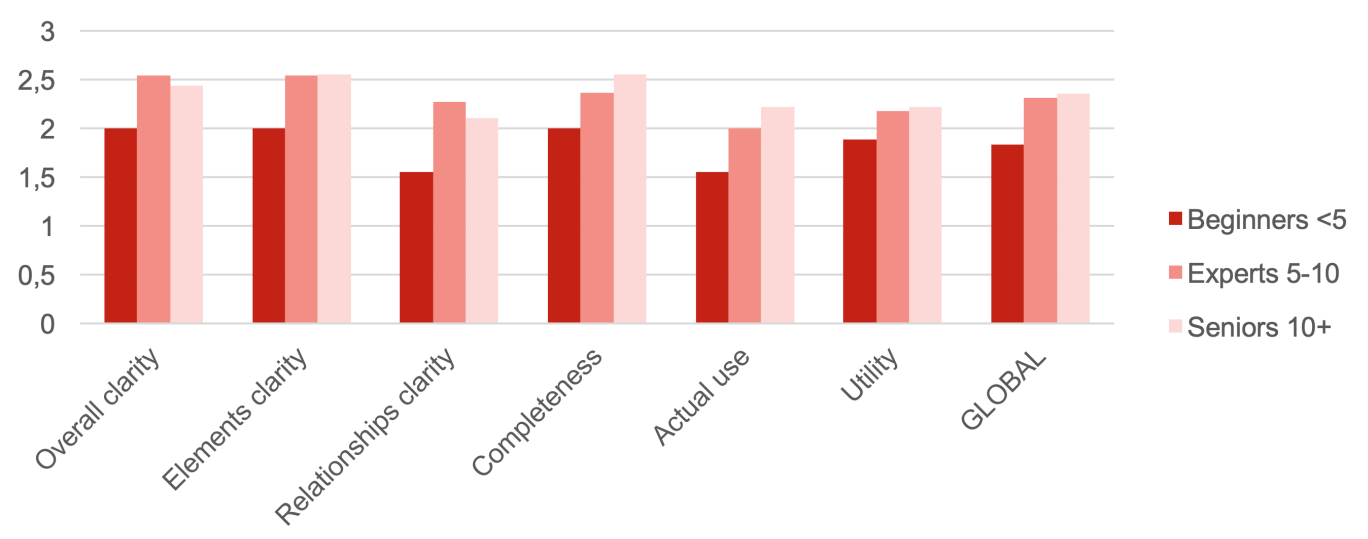

Figure 4: Model evaluation by experience (age of service; $N=29$ )

six items, and can be interpreted in at least two different ways. Given that age of service is largely related to age, we could infer that younger teachers do not need so much support in the design of EERs (or of game-based experiences in general), so that the Star Model looks maybe interesting but practically pleonastic. On the contrary, we could infer that more experienced teachers have a more detailed awareness of the complexity of game-based learning, and therefore appreciate more the model's support. While not conducted in a structured way, the observation of the EERs designed by the participants during the courses seem to support the second hypothesis.

\section{Discussion and conclusion}

\subsection{About the Star model}

The Star Model was developed in the framework of the School Break Erasmus+ project as a support to EERs design. It brings together insights from the previous work of scholars and game design and ERs/game-based learning (e.g., [13, 23]), and its key aim is providing an overview of the internal game elements and of its context, in order to support the consistent design of meaningful play [24]. We believe that the Star Model provides new insights to EER design and development, as it organizes its elements on two layers (game elements and contextual elements) and brings their interconnections to the foreground. Also, it focuses on game-flow and constraints as important design elements.

To the extent of our knowledge, this model is one of the first design tools intended to support the design of EERs. While other models are available, like EscapED, this one overcomes some limitations and provides a useful alternative. Game design is no formal science, and of course other models can and will be proposed to emphasize different aspects, or introduce new perspectives on the design process. As in other disciplines, the variety of available models offers a broader and richer palette to designers. Starting in the early '90, many models were developed for example in the domain of Instructional Design \& Development [36]. In a 1991 review [37], the author noted that "models vary widely in their purposes, amount of detail provided, and the technical jargon they contain" (p.4) so that "developers should be in the position of selecting an appropriate model. As has been noted in other contexts, if the only tool you have is a hammer, you tend to treat everything like a nail." (p. 48). We therefore believe that a new model, if tested and validated, always opens up new design and thinking 
spaces.

The results presented in this paper indicate that the Star Model makes sense to teachers, and could be used as a starting point for their training in EERs design. As the model is disseminated, more data will be collected and more insights will be available to improve it for example to make it simpler, or graphically clearer and more appealing.

\subsection{About the validation}

In order to validate the Star Model, we surveyed 50 teachers after an EER course about the clarity (overall, of individual elements, and of the relationships among the elements), completeness, utility and actual use of the model; for 24 of them we also measured their selfassessment in EERs use and design skills. This corresponds to an internal validation of the model, as it does not refer to products or activities developed with the model itself, but to its formal features and perception by its users [35], i.e., it focuses on the "integrity of the model and its use" (p. 737). As there is no unique and agreed-upon reference, our validation is based on data collected through ad hoc surveys developed by the authors, focusing on the parameters listed above, which match the key dimensions of internal evaluation, namely the model components and use [35]. This choice entails two limitations that should be taken into account: first, the validation questions were chosen by the authors, and cannot be directly compared to other studies; second, our data are self-evaluations, which are always subject to bias and often differ from third-person evaluations; Moreover, due to organizational reasons, the pre-course survey was not delivered in course A, which may have an impact on the results and make them slightly less comparable.

Nonetheless, our study shows overall positive results in both the course design and implementation, and in the explicit model evaluation, and suggests that the model can be proposed as a valid tool for EERs design. The model evaluation items yielded different results between primary and secondary school teachers, and between teachers with fewer years of service (beginners) with respect to teachers with more years of service. While such differences are not unexpected considering how diverse are these professional groups, they stimulate questions to drive further investigation on EERs, and more in general, on game-based learning.

\subsection{Outlooks}

Further investigation questions also emerge from this paper and from the observation of teachers' EERs designs. For example, what are the most common pitfalls that teachers encounter in EERs design? Are there subject matters, topics or competences that more easily fit the EER format? What elements in the model require more attention in order to be grasped by teachers and actually integrated in the design? Such research questions should be pursued to investigate the design issues connected to the educational use of escape rooms and boxes, which should be considered alongside the evaluation of their instructional affordances and impact.

Another interesting research direction could be the direct comparison of different EER design models. Are there differences in the learning curve or in the understanding of the model? Do they better fit different school levels, subjects or situations?

\section{Acknowledgments}

We wish to thank all the partners in the SchoolBreak projects. The SchoolBreak project is supported by the Erasmus+ programme of the European Commission, and in Switzerland by the Movetia Foundation. We are also grateful for the insightful and constructive feedback of the anonymous reviewers. 


\section{References}

[1] S. Nicholson, "The state of escape: Escape room design and facilities," Presented at Meaningful Play, 2016. [Online]. Available: http://scottnicholson.com/pubs/ stateofescape.pdf

[2] S. Nicholson, "Creating engaging escape rooms for the classroom," Official Journal of Childhood Education Int., vol. 94, no. 1, pp. 44-49, 2018. doi: http://dx.doi.org/10.1080/00094056.2018.1420363

[3] WEF, New Vision for Education: Unlocking the Potential of Technology. Davos: World Economic Forum, 2015. [Online]. Available: http://www3.weforum.org/docs/ WEFUSA_NewVisionforEducation_Report2015.pdf

[4] A. Veldkamp, J. Daemen, S. Teekens, S. Koelewijn, M.-C. P. J. Knippels, and W. R. van Joolingen, "Escape boxes: Bringing escape room experience into the classroom," British Journal of Educational Tech., vol. 51, no. 4, pp. 1220-1239, 2020. doi: https://doi.org/10.1111/bjet.12935

[5] D. Menon and M. Romero, Game Mechanics Supporting a Learning and Playful Experience in Educational Escape Games. IGI Global, 2019, ch. 7, pp. 143-162, doi: https://doi.org/10.4018/978-1-7998-2015-4.ch007.

[6] M. Hermanns et al., "Using an "escape room" toolbox approach to enhance pharmacology education," Journal of Nursing Education and Practice, vol. 8, no. 4, pp. 89-95, 2018. doi: https://doi.org/10.5430/jnep.v8n4p89

[7] A. E. Kinio, L. Dufresne, T. Brandys, and P. Jetty, "Break out of the classroom: the use of escape rooms as an alternative teaching strategy in surgical education," Journal of surgical education, vol. 76, no. 1, pp. 134-139, 2019. doi: https://doi.org/10.1016/j.jsurg.2018.06.030

[8] A. I. V. Vörös and Z. Sárközi, "Physics escape room as an educational tool," in AIP Conference Proceedings, vol. 1916, no. 1. AIP Publishing LLC, 2017. doi: https://doi.org/10.1063/1.5017455 p. 050002.

[9] M. Csikszentmihalyi, Flow and the foundations of positive psychology: The collected works of Mihaly Csikszentmihalyi. Berlin: Springer, 2014, doi: https://doi.org/10.1007/978-94-017-9088-8.

[10] C. Giang et al., "Exploring escape games as a teaching tool in educational robotics," in Proc. of EDUROBOTICS conf., 2018. doi: https://doi.org/10.1007/978-3-030-181413_8 pp. 95-106.

[11] S. López-Pernas, A. Gordillo, E. Barra, and J. Quemada, "Examining the use of an educational escape room for teaching programming in a higher education setting," IEEE Access, vol. 7, pp. 31 723-31 737, 2019. doi: https://doi.org/10.1109/access.2019.2902976

[12] P. Fotaris and T. Mastoras, "Escape rooms for learning: A systematic review," in Proc. of the 13th Int. Conf. on Game Based Learning, 10 2019. doi: https://doi.org/10.34190/GBL.19.179 pp. 235-243.

[13] S. Clarke, D. Peel, S. Arnab, L. Morini, H. Keegan, and O. Wood, "Escaped: A framework for creating educational escape rooms and interactive games to for higher/further education," International Journal of Serious Games, no. 4(3), pp. 73-86, 2017. [Online]. Available: https://dx.doi.org/10.17083/ijsg.v4i3.180

[14] School Break, Using Educational Escape Rooms in Class. School Break Handbook 1. School Break Project, 2019. [Online]. Available: http://www.school-break.eu/ wp-content/uploads/2020/03/SB_Handbook_1_eER_use_in_teaching.pdf

[15] School Break, Designing Educational Escape Rooms. School Break Handbook 2. School Break Project, 2019. [Online]. Available: http://www.school-break.eu/ wp-content/uploads/2020/03/SB_Handbook_2_desinging_eERs.pdf 
[16] School Break, Designing Escape Rooms in Class. School Break Handbook 3. School Break Project, 2019. [Online]. Available: http://www.school-break.eu/wp-content/ uploads/2020/03/SB_Handbook_3_learning_through_designing2.pdf

[17] A. J. Corkill, "Advance organizers: Facilitators of recall," Educational Psychology Review, vol. 4, no. 1, pp. 33-67, 1992. [Online]. Available: http://www.jstor.org/stable/ 23359577

[18] R. Garris, R. Ahlers, and J. E. Driskell, "Games, motivation, and learning: A research and practice model," Simulation \& gaming, vol. 33, no. 4, pp. 441-467, 2002. [Online]. Available: http://www.brainadvantage.com/PDF/Games, Motivation, andLearning.pdf

[19] O. Heikkinen and J. Shumeyko, "Designing an escape room with the experience pyramid model," Haaga-Helia ammattikorkeakoulu, Bachelor Thesis, 2016. [Online]. Available: https://www.theseus.fi/handle/10024/112798

[20] H. N. Eukel, J. E. Frenzel, and D. Cernusca, "Educational gaming for pharmacy students - design and evaluation of a diabetes-themed escape room," American Journal of Pharmaceutical Education, vol. 81, no. 7, 2017. doi: https://doi.org/10.5688/ajpe8176265

[21] H. Wise, J. Lowe, A. Hill, L. Barnett, and C. Barton, "Escape the welcome cliché: Designing educational escape rooms to enhance students' learning experience." Journal of Information Literacy, vol. 12, no. 1, 2018. doi: https://doi.org/10.11645/12.1.2394

[22] B. L. Morrell and H. M. Ball, "Can you escape nursing school? educational escape room in nursing education," The Research Journal of the National League for Nursing, vol. 41, no. 3, pp. 197-198, 2020. doi: https://doi.org/10.1097/01.nep.0000000000000441

[23] K. Salen and E. Zimmermann, Rules of play: Game design fundamentals. Boston, MA: MIT Press, 2004, doi: https://doi.org/10.1177/1470357205048940.

[24] S. Nicholson, "Ask why: creating a better player experience through environmental storytelling and consistency in escape room design," Meaningful Play, pp. 1-17, 2016. [Online]. Available: http://scottnicholson.com/pubs/askwhy.pdf

[25] G. R. Morrison, S. J. Ross, J. R. Morrison, and H. K. Kalman, Designing effective instruction. John Wiley \& Sons, 2019, doi: https://doi.org/10.1007/BF02504995.

[26] H. Jenkins, "Game design as narrative architecture," Computer, vol. 44, no. 53, pp. 118 130, 2003.

[27] S. Nicholson, "Peeking behind the locked door: A survey of escape room facilities," Whitepaper, 2015. [Online]. Available: http://scottnicholson.com/pubs/erfacwhite.pdf

[28] N. Whitton, "Playful learning: tools, techniques, and tactics," Research in Learning Technology, vol. 26, 2018. doi: https://doi.org/10.25304/rlt.v26.2035

[29] M. Wiemker, E. Elumir, and A. Clare, "Escape room games," Game Based Learning, vol. 55, pp. 55-75, 2015. [Online]. Available: http://skill.fhstp.ac.at/wp-content/ uploads/2016/05/Tagungsband_2015.pdf

[30] PlayThinkLearn, "Eduscapes," http://eduscapes.playthinklearn.net/, 2016, accessed: 2020-04-02.

[31] A. S. Gibbons, An architectural approach to instructional design. New York: Routledge/Taylor \& Francis Group, 2014, doi: https://doi.org/10.4324/9780203075203.

[32] S. Arnab and S. Clarke, "Towards a trans-disciplinary methodology for a game-based intervention development process," British journal of educational technology, no. 48(2), pp. 279-312, 2017. doi: https://doi.org/10.1111/bjet.12377

[33] A. Betrus and L. Botturi, "Principles of using simulations and games for teaching," in Playing Games in Schools: Engaging Learners through Interactive Entertainment, A. Hirumi, Ed. International Society for Technology in Education, 2010, pp. 33-55.

[34] B. L. Brathwaite and I. Schreiber, Challenges for Game Designers. Nelson Education, 2009. [Online]. Available: http://www.dreamco.com/challenges.pdf 
[35] R. C. Richey, "Validating instructional design and development models," Innovations in instructional technology: Essays in honor of M. David Merrill, pp. 171-185, 2005. doi: https://doi.org/10.4324/9781410613684

[36] R. M. Branch and T. A. Dousy, Survey of instructional design models, 5th edition. Association for Educational Communications and Technology, 2015.

[37] K. L. Gustafson and G. C. Powell, Survey of instructional development models with an annotated ERIC bibliography. ERIC, 1991. 


\section{A ANNEX 1. ABOUT ESCAPE ROOMS (pre-course survey)}

- Gender (M/F)

- In what school sector are you employed? (Primary school / Secondary school)

- If you teach in secondary schools, what is your main subject? (List of subjects)

- How long have you been teaching? (Less than 3 years / Between 3 and 5 years / Between 5 and 10 years / More than 10 years)

- Escape room experience (Possible answer for each item: Many times / 1 time only / Never)

- Have you ever played an ER, whether for fun or learning?

- Have you ever led an ER designed by others as game master?

- Have you ever designed an ER, whether for fun or learning?

- Have you ever designed an ER with your pupils?

- Serious games experience (Possible answer for each item: Many times / 1 time only / Never)

- Have you ever used game-based activities in class (quizzes, scavenger hunts, memory, etc.)?

- Have you ever designed game-based activities in class (quizzes, scavenger hunts, memory, etc.)?

- Have you ever used game-based activities with your pupils?

- Do you have any other game-based learning experiences that you deem relevant for this course? (open answer)

- Why are you interested in escape rooms? (open answer)

- What do you expect from this course? (open answer)

- To what extent do you agree with the following statements? (Likert scale from $0=$ completely disagree to $3=$ completely agree)

- I know where I can find good ER for my class

- I know where to find resources to create good ERs

- I know how to prepare for using an ER in my class

- I feel at ease in conducting an ER in class as game master

- I know how to integrate and ER in a learning unit

- I know how to get the most learning for my pupils from an ER

- I know how to use an ER for the evaluation of my pupils

- I can design a new ER

\section{B ANNEX 2: ABOUT ESCAPE ROOMS (post-course survey)}

- Gender (M/F)

- In what school sector are you employed? (Primary school / Secondary school)

- After this course, how useful do you think escape rooms are for teaching and learning? (open answer)

- In general, did the course met your expectations? (I learned more than I expected / I learned what I expected / I learned less than I expected / Other: ...)

- To what extent do you agree with the following statements? (Likert scale from $0=$ completely disagree to $3=$ completely agree)

- I know where I can find good ER for my class

- I know where to find resources to create good ERs

- I know how to prepare for using an ER in my class

- I feel at ease in conducting an ER in class as game master 
- I know how to integrate and ER in a learning unit

- I know how to get the most learning for my pupils from an ER

- I know how to use an ER for the evaluation of my pupils

- I can design a new ER

- To what extent do you agree with the following statements? (Likert scale from $0=$ completely disagree to $3=$ completely agree)

- I think I'll use ER with my pupils

- I'd like to design new educational ER

- I'd like to design a new ER with my pupils

- I'd like another course on this topic

- I'd recommend this course to a colleague

- During this course, we used the Star Model, that is illustrated in the picture [picture]. The following questions are about this design model.

- To what extent do you agree with the following statements? (Likert scale from $0=c o m-$ pletely disagree to $3=$ completely agree)

- The model overall looks clear to me

- The elements in the model are clear to me

- The model includes all the key elements on which we worked

- The model helps understanding the relationships among its elements

- During the design, we actually used the model for reference

- In general I think this model is usable

- Do you think that something important is missing from the model, or do you have any suggestion for improvement? (open answer) 